\title{
Ferrocenyl-substituted fluorescent anthracenes and anthraquinones
}

\author{
Ian R. Butler, ${ }^{\text {a,* }}$ Alfonso G. Callabero, ${ }^{a}$ Glenn A. Kelly, ${ }^{a}$ Jennifer R. Amey, ${ }^{a}$ \\ Tobias Kraemer, ${ }^{\mathrm{a}}$ Dafydd A. Thomas, ${ }^{\mathrm{a}}$ Mark E. Light, ${ }^{\mathrm{b}}$ Thomas Gelbrich ${ }^{\mathrm{b}}$ \\ and Simon J. Coles ${ }^{\mathrm{b}, *}$ \\ ${ }^{a}$ Department of Chemistry, University of Wales, Bangor, Gwynedd LL57 2UW, UK \\ ${ }^{\mathrm{b}}$ Department of Chemistry, The University of Southampton, Highfield, Southampton, UK
}

Received 21 May 2003; revised 24 October 2003; accepted 7 November 2003

\begin{abstract}
The synthesis of a range of ferrocene-substituted ethynylanthracenes and 1,1'-(bis-(2-ethenylanthraquinoyl)ferrocene has been achieved. The synthesis relies on the production of ferrocenylanthraquinones as key precursors. The products were obtained in the reactions of ferrocenylanthraquinones with phenylethynyllithium or trimethylsilylethynyllithium followed by reduction with tin chloride. The key products such as 1- and 2-ferrocenyl(9,10-bis-phenylethynyl)anthracenes have been characterised by X-ray single crystal diffraction.
\end{abstract}

(C) 2003 Elsevier Ltd. All rights reserved.

\section{Introduction}

The design and synthesis of compounds for applications in material science, both molecular and supramolecular, for use in sensor chemistry and optoelectronics is an important and topical area of research. ${ }^{1}$ The construction of such molecules is dependent on the availability of key molecules, which have useful physical or chemical properties, for example, light or heat sensitivity, redox or $\mathrm{pH}$ activity, selective binding etc. Such molecules include crown ethers, ${ }^{2}$ cryptands, ${ }^{3}$ metallocenes, ${ }^{4}$ bipyridines ${ }^{5}$ and quinones. ${ }^{6}$ The combination of two such active molecules should lead to compounds with both interesting structural and material properties. We and others have been especially interested in the combination of ferrocene with a range of such active molecules for many years. Ferrocenes and their derivatives are widely used in material science because of their inherent reductive and photochemical stability and additionally because of their clean electrochemistry. ${ }^{7}$ Our research has two main objectives in this area, which are the synthesis of ferrocene-containing luminescent molecules and of ferrocene donor-acceptor molecules. The former

\footnotetext{
Keywords: Ferrocene; Anthraquinone; Anthracene.

* Corresponding authors. Tel.: +44-1248-382390; fax: +44-1248-370528 (I.R.B.); tel.: +44-2380-596722; fax: +44-2380-596723 (S.J.C.); e-mail addresses: i.r.butler@bangor.ac.uk; s.j.coles@soton.ac.uk
}

may seem something of a contradiction in that ferrocene is a well known to be a fluorescence quencher, however it is also well established that on oxidation of the iron centre this quenching is mitigated and that the intramolecular inclusion of ferrocene may not lead to quenching. ${ }^{8}$ Thus it should be possible to develop electro-optical switching devices based on this premise.

One particularly interesting area of investigation is in the synthesis and characterisation of substituted quinones, anthraquinones and anthracenes. Recently a description of the direct synthesis of ferrocenylquinones ${ }^{9}$ has been published using a synthetic procedure beginning with appropriately substituted cyclobutenes and lithioferrocenes, while ferrocenylanthracenes ${ }^{10}$ and ferrocenylanthraquinones ${ }^{11}$ have been known for a considerable time. 1-Ferrocenylanthraquinone is prepared directly from ferrocene from the diazonium FAST RED AL salt, although this literature isolation procedure is tedious, ${ }^{12}$ as considerable quantities of anthraquinone and 1-hydroxyanthraquinone are also formed, which tend to precipitate and which are difficult to remove by chromatography, particularly when the reaction is carried out on a large scale. Thus a slight modification to the literature method has been implemented to achieve cleaner reaction chemistry. The 2-ferrocenylanthraquinone can be similarly obtained with a slight modification to the reaction procedure, additional details of which are reported here. ${ }^{13}$ 


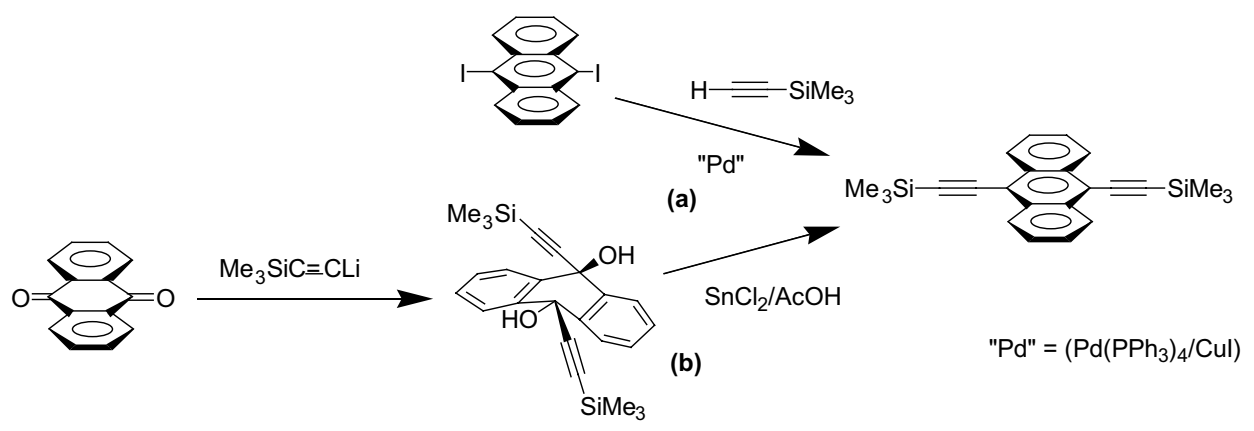

Scheme 1.

In the case of fluorescent molecules one class of molecules is of special interest to us, which are the aryl- and alkynylanthracenes and their precursor anthraquinones. ${ }^{14}$ 9,10-Bis-arylalkynylanthracenes are used in commercial lightsticks as the fluorescence agents ${ }^{15}$ in combination with the fuel source, normally diarylperoxylates and hydrogen peroxide. The best literature syntheses of these molecules to date are from the reactions of 9,10-dibromoanthracenes (or diiodoanthracenes $^{16}$ ) and the appropriate arylalkyne using palladium catalysed coupling, Scheme $1 \mathrm{a}^{17}$ although an earlier alternative synthetic method, which involves the reaction of anthraquinones with alkynyllithiums followed by reduction of the product trans-diols with either stannous chloride or phosphate is also available, Scheme $1 \mathrm{~b} .{ }^{18}$

One other class of compounds, which are currently under investigation are ethenylanthraquinones, which undergo photochemical cis-trans isomerisation according to Scheme $2 .{ }^{19}$ In recent work a ferrocene analogue, 1, also shown in Scheme 2, of these compounds has been reported together with further derivatives of this molecule, ${ }^{20}$ however the more interesting disubstituted ferrocene compound was not investigated. We have also been active in this area and we now report the synthesis and characterisation of the disubstituted ferrocene compound.

In the initial synthetic studies a comparison of the two synthetic methods towards the alkyne-substituted anthracenes was made using trimethylsilylethyne as the alkyne group and the crystallographic structures of an intermediate diol $\mathbf{2}$ and an alkyne $\mathbf{3}$ were determined to provide structural information for modeling (Figs. 1 and 2). The two synthetic methods were found to be equally effective in terms of ease of use and overall yield. In
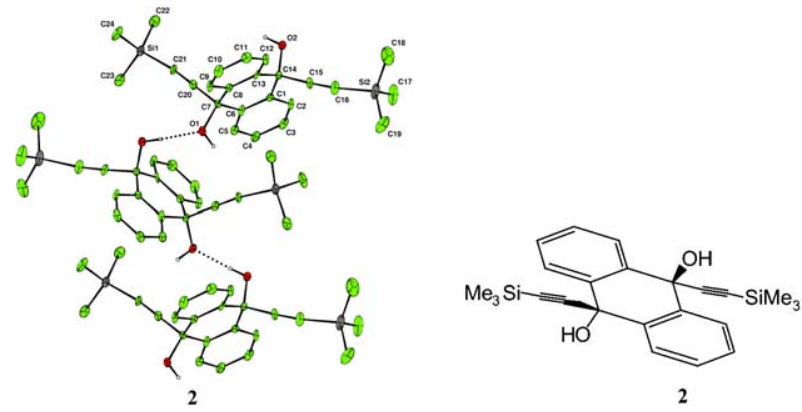

Figure 1. Molecular structure of 2 showing the hydrogen bonded chains that extend along the $b$-direction. Nonhydroxyl hydrogen atoms have been omitted for clarity and thermal ellipsoids drawn at the $35 \%$ probability level. The data have been deposited at the Cambridge Crystallographic Centre CCDC 210617.

accord with the literature data, the trans diols are the main products, although the cis isomers were also observed in the crude reaction products by NMR analysis. There is evidence for strong hydrogen bonding in the solid state structures of the trans products, for example, as shown in Figure 1. The direct reaction of the anthraquinones with alkynyllithiums was selected for the synthesis of the ferrocene-substituted molecules because of the ready availability of the anthraquinone precursors and the difficulties encountered in the preparation of the iodo-substituted ferrocenylanthracenes.

\section{Monosubstituted ferrocenes}

The two monosubstituted 1- and 2-ferrocenylanthraquinone starting reagents $\mathbf{4}$ and $\mathbf{5}$ were prepared by a

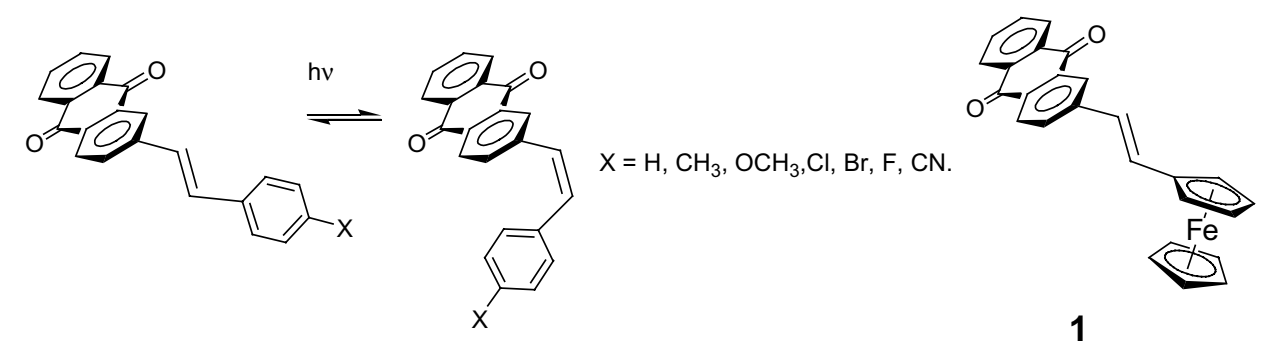




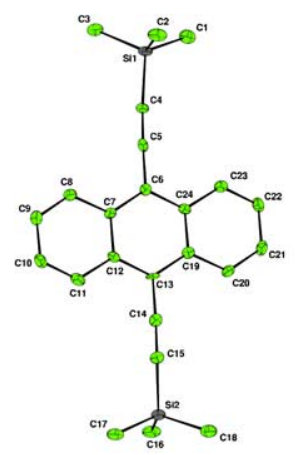

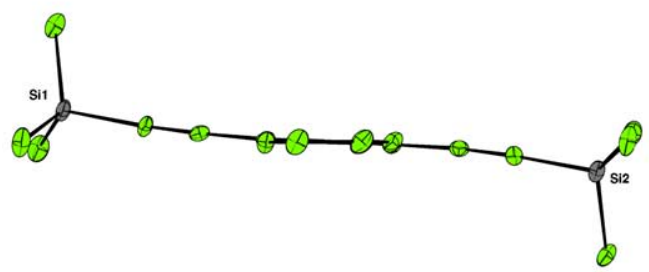

3

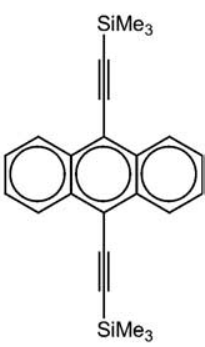

3

Figure 2. Molecular structure of one of the two independent molecules of $\mathbf{3}$ in the asymmetric unit that differ slightly in the flex of the molecule. Hydrogen atoms have been omitted for clarity and thermal ellipsoids drawn at the $35 \%$ probability level. The data have been deposited at the Cambridge Crystallographic Centre CCDC 210618.

modification of the literature methods. ${ }^{12,13}$ The optimum preparative method was the use of palladium-catalysed couplings of ferrocenylboronic acid ${ }^{21}$ or ferrocenyl zinc chloride with bromoanthraquinones, although we used the diazonium arylation route where large quantities of compounds $>25 \mathrm{~g}$ were required. It then proved relatively easy to obtain the 1 -ferrocene-substituted diarylanthracenes from the direct reaction of an aryllithium reagent followed by reduction of the product trans-diol, with or without isolation, using stannous chloride. These compounds were obtained as bright orange or orange-red solids, 6 and 7, Scheme $3 .{ }^{22}$

The reaction of the 1- and 2-ferrocenylanthraquinones with trimethylsilylethynyllithium afforded the trans-diols $\mathbf{8}$ and 10, which were subsequently reduced by tin chloride to their corresponding ferrocenylanthracenes 9 and 11 (Scheme 4). Deprotection of the TMS alkyne 9 could be carried out both by the standard hydroxide method or by using ammonium tetrafluoroborate, the latter being preferable, although the unprotected alkyne was found to be extremely air and light sensitive and was difficult to isolate by chromatography without special precautions. ${ }^{23}$

The phenylethynyl-substituted compounds $\mathbf{1 3}$ and 15 were subsequently prepared via the trans-diols $\mathbf{1 2}$ and $\mathbf{1 4}$ by the same method beginning with compounds 4 and 5 using phenylethynyllithium as the reagent. ${ }^{24}$ Both phenylethynyl products were crystallographically characterised. One of these isomers is shown in Figure 3 (13: CCDC 210616, 15: CCDC 208150).

We have found as a practical synthetic method that the product alkynes may be obtained in all cases without isolation of the diols in a one pot procedure.

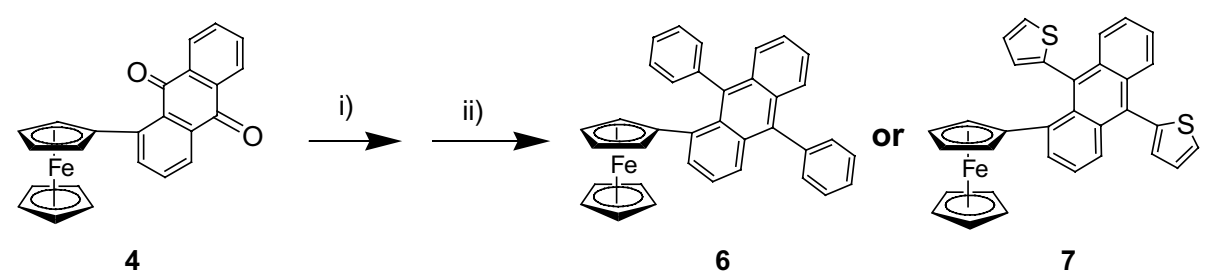

Scheme 3. Reagents and conditions: (i) phenyllithium or 2-thienyllithium/ $\mathrm{H}_{2} \mathrm{O}$; (ii) $\mathrm{SnCl}_{2} /$ acetic acid; 6 65\% overall, $757 \%$ overall.

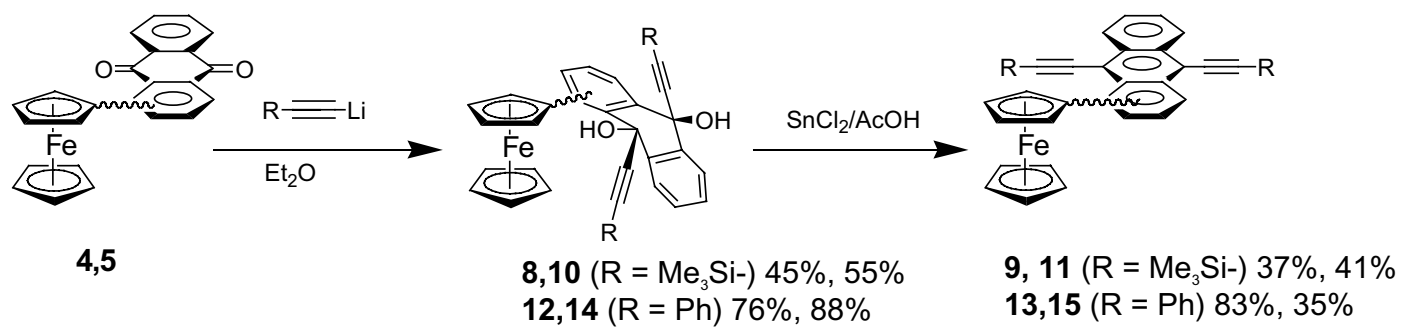




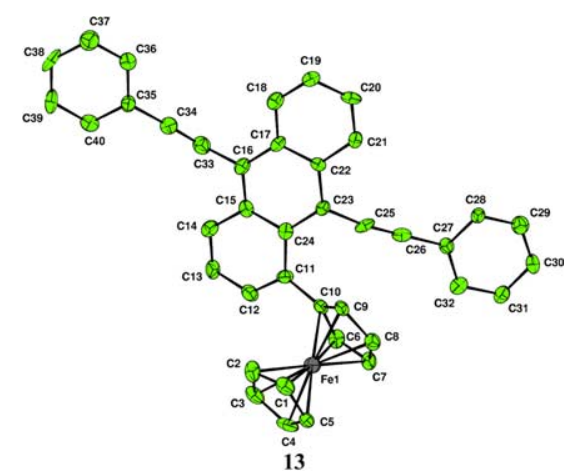

Figure 3. Molecular structure of 13. Hydrogens have been omitted for clarity and thermal ellipsoids drawn at the $35 \%$ probability level. The data have been deposited at the Cambridge Crystallographic Centre CCDC 210616.

The extension of this reaction for the synthesis of the disubstituted compounds $\mathbf{1 6}$ and $\mathbf{1 7}$ beginning with bis$1,1^{\prime}$-(2-anthraquinoyl)ferrocene was similarly successful although neither of these compounds have been crystallographically characterised as yet since they tend to form deep red/black fine crystalline powders. In this case the precursor bis-anthraquinolylferrocenes were more difficult to obtain compared to the monosubstituted derivatives in that palladium-catalysed coupling of the disubstituted tri- $n$-butylstannylferocenes and ferrocenyl zinc chlorides were ineffective and the only reactions, which were effective were the diazonium salt route or the Suzuki coupling reactions both of which were low yielding (Scheme 5).
Finally, as mentioned in the Introduction, we have successfully obtained the bis-1,1'-(2-ethenylanthraquinonyl)ferrocene $\mathbf{1 8}^{25}$ from the reaction of ferrocene $1,1^{\prime}$ bis-carbaldehyde with [(2-anthraquinonyl)methyl]triphenylphosphonium bromide following a modified literature procedure, which had been used for the preparation of the monosubstituted compound, $1 .{ }^{20}$ Interestingly, on isolation of the product by chromatography it was apparent that several geometric isomers were present. Recrystallisation of the crude sample however afforded a crystalline sample of the predominant trans-trans isomer, which has also been structurally characterised, Figure 4.

In conclusion, we have been able to prepare key compounds in the quest for redox-active light emitters and photochemically active ferrocenes. Future investigations will be tailored towards applications of these molecules in material science. In preliminary experiments it has been observed that these compounds may be used successfully as fluorescers in chemiluminescence.

\section{Acknowledgements}

Mass spectroscopic data used in the characterisation of all new compounds was measured by the EPSRC mass spectrometry service at the University of Wales, Swansea. Funding for this project, from the University of Wales, Bangor, is gratefully acknowledged.

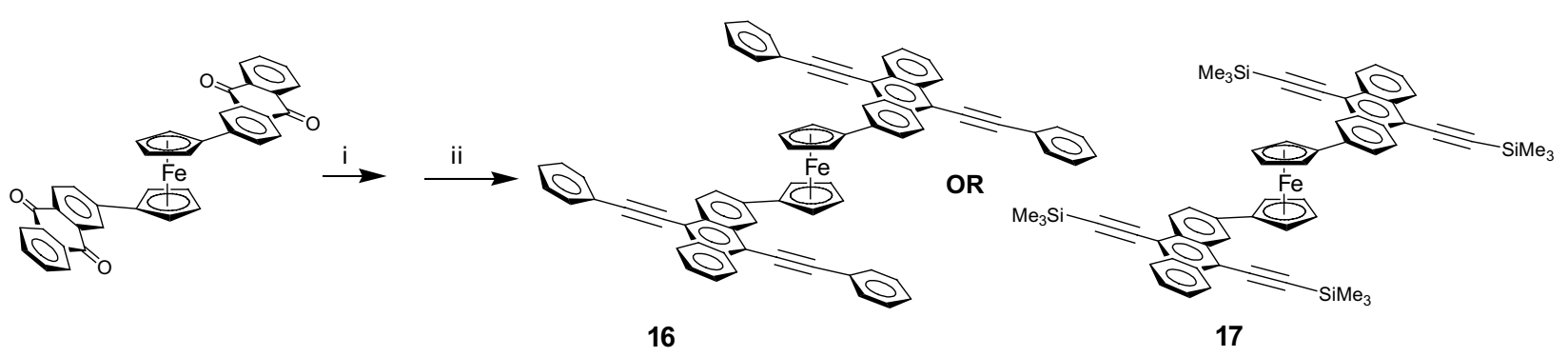

Scheme 5. Reagents and conditions: (i) $\mathrm{R}-\mathrm{C} \equiv \mathrm{C}-\mathrm{Li}$, ether; (ii) $\mathrm{SnCl}_{2} / \mathrm{AcOH}$; $1653 \%$ overall, $1732 \%$ overall.
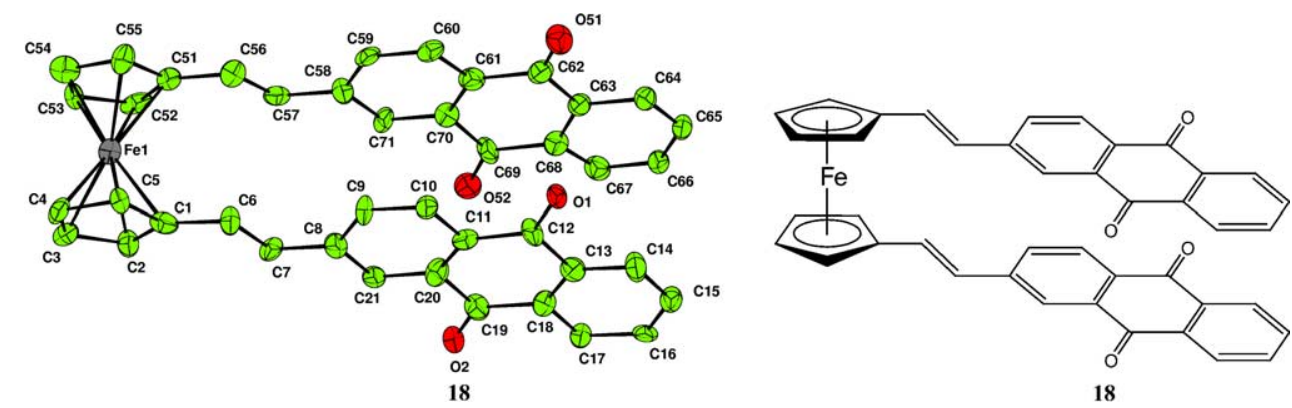

Figure 4. Molecular structure of 18. Hydrogens have been omitted for clarity and thermal ellipsoids drawn at the $35 \%$ probability level. The data have been deposited at the Cambridge Crystallographic Centre CCDC 210615. 


\section{References and Notes}

1. (a) Inorganic Materials; Bruce, D. W., O’Hare, D., Eds.; Wiley: Chichester, 1992; (b) Electrochromism; Monk, P. S., Mortimer, R. J., Rosseinsky, D. R., Eds.; VCH: Weinheim, 1995.

2. (a) Jimenez-Morales, A.; Galvan, J. C.; Aranda, P. Electrochim. Acta 2002, 47, 2281-2287; (b) Kampmann, B.; Lian, Y. Q.; Klinkel, M. L.; Vecchi, P. A.; Quiring, H. L.; Soh, C. C.; Sykes, A. G. J. Org. Chem. 2002, 67, 38783883; (c) Zeng, X. S.; Han, X. X.; Chen, L. X.; Li, Q. S.; Xu, F. B.; He, X. W.; Zhang, Z. Z. Tetrahedron Lett. 2002, 43, 131-134; (d) Su, N.; Bradshaw, J. S.; Zhang, X. X.; Song, H.; Savage, P. B.; Xue, G. P.; Krakowiak, K. E.; Izatt, R. M. J. Org. Chem. 1999, 64, 8855-8861; (e) Atwood, J. L.; Holman, K. T.; Steed, J. W. Chem. Commun. 1996, 1401-1407; (f) Kubo, Y.; Tokita, S.; Kojima, Y.; Osano, Y. T.; Matsuzaki, T. J. Org. Chem. 1996, 61, 3758-3765.

3. (a) Carr, J. D.; Coles, S. J.; Hursthouse, M. B.; Tucker, J. H. R. J. Organomet. Chem. 2001, 637, 304-310; (b) Costa, J.; Delgado, R.; Drew, M. G. B.; Felix, V.; Saint-Maurice, A. J. Chem. Soc., Dalton Trans. 2000, 1907-1916.

4. (a) Coles, S. J.; Denuault, G.; Gale, P. A.; Horton, P. N.; Hursthouse, M. B.; Light, M. E.; Warriner, C. N Polyhedron 2003, 22, 699-709; (b) Arimori, S.; Ushiroda, S.; Peter, L. M.; Jenkins, A. T. A.; James, T. D. Chem. Commun. 2002, 2368-2369; (c) Kim, C.; Park, E.; Song, C. K.; Koo, B. W. Synth Met. 2001, 123, 493-496; (d) Gale, P. A.; Hursthouse, M. B.; Light, M. E.; Sessler, J. L.; Warriner, C. N.; Zimmerman, R. S. Tetrahedron Lett. 2001, 42, 6759-6762; (e) Lahav, M.; Katz, E.; Willner, I. Electroanalysis 1998, 10, 1159-1162; (f) Ueno, A.; Chen, Q.; Suzuki, I.; Osa, T. Anal. Chem. 1992, 64, 1650-1655.

5. (a) Best, M. D.; Anslyn, E. V. Chem. Eur. J. 2003, 9, 5157; (b) Cary, D. R.; Darrow, C. B.; Lane, S. M.; Peyser, T. A.; Satcher, J. H.; Van Antwerp, W. P.; Nelson, A. J.; Reynolds, J. G. Sens. Actuator B-Chem. 2002, 87, 25-32; (c) Richardson, J. N.; Dyer, A. L.; Stegemiller, M. L.; Zudans, I.; Seliskar, C. J.; Heineman, W. R. Anal. Chem. 2002, 74, 3330-3335; (d) Moutet, J. C.; Popescu, A.; SaintAman, E.; Tomaszewski, L. Electrochim. Acta 1998, 43, 2257-2262; (e) Mutai, T.; Abe, Y.; Araki, K. J. Chem. Soc., Perkin Trans. 2 1997, 1805-1809.

6. (a) Ataman, D.; Akkaya, E. U. Tetrahedron Lett. 2002, 43, 3981-3983; (b) Ziessel, R. Incl. Phenom. Macrocycl. Chem. 1999, 35, 369-379; (c) Kaku, T.; Okamoto, Y.; Charles, L.; Holness, W.; Karan, H. I. Polymer 1995, 36, 2813 2818.

7. Fery-Forgues, S.; Delavaux-Nicot, B. J. Photochem. Photobiol. A: Chem. 2000, 132, 137-159.

8. Duggen, D. M.; Hendrickson, D. N. Inorg. Chem. 1975, 14, 955-970.

9. Zora, M.; Yucel, B.; Acikalin, S. Tetrahedron Lett. 2003 44, 2237-2241.

10. (a) Gonzalo, V.; Coudret, C.; Patoux, C.; Launay, J. P. C.R. Acad. Sci. Ser. IIC: Chim. 1999, 2, 321-328; (b) Butler, I. R.; Hobson, L. J.; Coles, S. J.; Hursthouse, M. B.; Malik, K. M. L. A. J. Organomet. Chem. 1997, 540, 27-40; (c) Wagner, G.; Herrmann, R.; Scherer, W. J. Organomet. Chem. 1996, 516, 225-233.

11. Murata, M.; Fujita, T.; Yamada, M.; Kurihara, M.; Nishihara, H. Chem. Lett. 2000, 1328-1329.

12. Roberts, R. M. G. J. Organomet. Chem. 1990, 388, 181186.

13. The diazonium salt is obtained using nitrosylsulfuric acid as the diazotising reagent, which gives rise to a more reactive salt than commercially available FAST RED AL salt.
14. (a) Hanela, P. J.; Brenton, P. D. Aust. J. Chem. 1981, 34, 1669-1685; (b) Hanela, P. J.; Brenton, P. D. Aust. J. Chem. 1981, 34, 1687-1700; (c) Hanela, P. J.; Brenton, P. D. Aust. J. Chem. 1981, 34, 1701-1717.

15. (a) Rauhult, M. M.; Roberts, B. G.; Maulding, D. R.; Bergmark, W.; Coleman, R. J. J. Org. Chem. 1975, 40, 330-335; (b) Rauhult, M. M. Acc. Chem. Res. 1969, 2, 8087.

16. In our research we have used 9,10-diiodoanthracene as a more suitable precursor because the palladium-catalysed reaction can be carried out at room temperature and the yields are consequently higher. The drawback to this is there has not been a high yielding synthesis of diiodoanthracene. We prepared this compound in a simple and high yielding synthetic route from 9,10-dilithioanthracene by reaction with tri- $n$-butyltin chloride followed by the direct reaction with iodine. The overall yield was in excess of $90 \%$.

17. Nguyen, P.; Todd, S.; Vandenbiggelaar, D.; Taylor, N. J.; Marder, T. B.; Wittmann, F.; Friend, R. H. Synlett 1994, 299-301.

18. (a) Rio, G. Ann. Chim. (Paris) 1954, 9, 182-255; (b) Reid, W.; Donner, W.; Schegelmilch, W. Chem. Ber. 1961, 94, 1051-1058.

19. (a) Newill, A. K.; Utley, J. P. J. Chem. Soc., Chem. Commun. 1992, 50-51; (b) Listram, V. N.; Stasyunk, A. P. Zh. Obshch. Khim. 1985, 55, 756-759.

20. (a) Liu, S. G.; Perez, I.; Martin, N.; Echegoyen, L. E. J. Org. Chem. 2000, 65, 9092-9102; (b) Murata, M.; Fujita, T.; Yamada, M.; Kurihara, M.; Nishihara, H. Chem. Lett. 2000, 1328-1329.

21. Butler, I. R.; Caballero, A. G.; Kelly, G. A. Inorg. Chem. Commun. 2003, 6, 639-642.

22. A typical synthetic procedure is as follows: A solution of either phenyllithium or 2-thienyllithium (1 molequiv) in dry diethyl ether $(100 \mathrm{~mL})$ was cooled to ca. $-70^{\circ} \mathrm{C}$ and 0.4 mol equiv of the 1 -ferrocenylanthraquinone was added. After warming to room temperature the mixture was hydrolysed by addition of water $(\mathrm{ca} .50 \mathrm{~mL})$. The organic layer was then separated and the water layer was reextracted with several portions of ether until the extracts were pale coloured. The combined organic layers were then reduced in volume to a give a deep red oil. The resultant oil was suspended in a mixture of acetic acid/ water $(50 / 50,50 \mathrm{~mL})$ and diethyl ether $(50 \mathrm{~mL})$ and a large excess of tin chloride dihydrate ( 5 mol equiv) was added. The mixture was stirred for $10 \mathrm{~h}$. The organic layer was separated and further diethyl ether was added. The solution was then carefully washed with a dilute sodium carbonate solution before being reduced in volume and chromatographed on silica. The products $(50-65 \%)$ were isolated as bright orange solids eluting with a mixture of petrol and diethyl ether $(1: 1)$.

23. Typical procedure for the deprotection of silylacetylenes: example: 9,10 -bis(trimethylsilylethynyl)anthracene $(0.5 \mathrm{~g}$, $1.35 \mathrm{mmol})$ was dissolved in tetrahydrofuran $(50 \mathrm{~mL})$ in a Schlenk tube under nitrogen. Tetra- $n$-butylammonium fluoride $(0.71 \mathrm{~g}, 2.70 \mathrm{mmol})$ was added to the solution. An immediate colour change from orange to brown occurred. The solution was left to stir for $1 \mathrm{~h}$. The solution was then purified by column chromatography on silica using petrol as the eluent. The analogous ferrocenyl compounds can be treated similarly although the method has yet to be optimised because of the product sensitivity.

24. Example of the synthesis of ferrocenylanthracene diols: 2-ferrocenyl-9,10-bis(phenylethynyl)dihydroanthracenetrans-9,10-diol: A solution of phenylacetylene $(0.14 \mathrm{~g}$, $1.4 \mathrm{mmol})$ was added to dry diethyl ether $(100 \mathrm{~mL})$ in a Schlenk tube under nitrogen. The solution was cooled to 
$-78^{\circ} \mathrm{C}$ whereupon one equivalent of $n-\mathrm{BuLi}(0.6 \mathrm{~mL}$, $1.4 \mathrm{mmol}, 2.5 \mathrm{M}$ ) was cautiously added dropwise. The reaction mixture was left to stir under nitrogen at $-50^{\circ} \mathrm{C}$ for $30 \mathrm{~min}$. 2-Ferrocenylanthraquinone $(0.3 \mathrm{~g}, 0.7 \mathrm{mmol})$ was added directly to the cooled solution using a powder funnel. The reaction mixture was stirred for $2 \mathrm{~h}$. The solution was filtered, dried with anhydrous magnesium sulfate and the solvent was evaporated under reduced pressure yielding initially a brown viscous oil $(0.33 \mathrm{~g})$, which could be crystallised from a mixture of diethyl ether and pet. ether (40/60). IR, $v_{\max }$ (film) $/ \mathrm{cm}^{-1} 3623$ (3683), 2362 (2399), 1518 and 1418; ${ }^{1} \mathrm{H}$ NMR $\left(250 \mathrm{MHz}, \mathrm{CDCl}_{3}\right)$ $3.61(2 \mathrm{~s}, 2 \times \mathrm{OH}), 4.20(\mathrm{~s}, 5 \mathrm{H}), 4.61\left(\mathrm{pt}(\mathrm{dd}), 2 \mathrm{H}, J_{\mathrm{HH}}=\right.$ $1.9 \mathrm{~Hz}), 5.15\left(\mathrm{pt}(\mathrm{dd}), 2 \mathrm{H}, J_{\mathrm{HH}}=1.9 \mathrm{~Hz}\right), 7.47(\mathrm{~m}, 6 \mathrm{H})$, $7.64(\mathrm{~m}, 4 \mathrm{H}), 7.80(\mathrm{~m}, 4 \mathrm{H}), 8.67(\mathrm{~m}, 3 \mathrm{H})$; DIMS: $m / z(\%)$ 596 (15) M ${ }^{+}, 594$ (10), 562 (8), 494 (100). Accurate mass EI+: $597.1497 \Delta=-3.3 \mathrm{C}_{40} \mathrm{H}_{28} \mathrm{O}_{2}$ Fe. The product was also characterised by crystallography, details of which will be published separately. Yield $88 \%$.

Typical synthesis: preparation of 9,10-bis(phenylethynyl)2 -ferrocenylanthracene, 15. The crude diol obtained as above $(0.2 \mathrm{~g}, 0.33 \mathrm{mmol})$ was added and stirred at room temperature to a solution of acetic acid/water (50:50, $100 \mathrm{~mL}$ ) and left to stir until all the solid was dissolved. An excess of $\mathrm{SnCl}_{2}$ (5 mol equiv) was added via a powder funnel to the reaction mixture and the mixture was left to stir for $2 \mathrm{~h}$. The product was extracted with diethyl ether $(3 \times 100 \mathrm{~mL})$. TLC analysis (eluent petrol/diethyl ether 90:10) indicated the presence of four compounds, $\mathrm{Rf}$ values $0.77,0.67,0.37,0.19$ corresponding to 9,10 bis(phenylethynyl)anthracene, the title product, the semiquinone and the diol starting material, respectively. The combined extracts were dried and evaporated under reduced pressure to leave a red-brown solid, which was purified by column chromatography on silica using hexane/diethyl ether 9:1 as the eluent. Fractions were collected from the column into small vials and left open for solvent evaporation. Red crystals of the product were obtained $(35 \%) .{ }^{1} \mathrm{H}$ NMR $\left(250 \mathrm{MHz}, \mathrm{CDCl}_{3}\right): 4.13(5 \mathrm{H}$, s), $4.48\left(2 \mathrm{H}\right.$, pseudo t $\left.(\mathrm{dd}), J_{\mathrm{HH}}=1.9 \mathrm{~Hz}\right), 4.90(2 \mathrm{H}$, pseudo t (dd), $\left.J_{\mathrm{HH}}=1.9 \mathrm{~Hz}\right), 7.50\left(6 \mathrm{H}, \mathrm{dd},{ }^{3} J_{\mathrm{HH}}=7.6 \mathrm{~Hz}\right.$, $\left.{ }^{4} J_{\mathrm{HH}}=3.4 \mathrm{~Hz}\right), \quad 7.65\left(2 \mathrm{H}, \mathrm{dd},{ }^{3} J_{\mathrm{HH}}=7.0 \mathrm{~Hz},{ }^{4} J_{\mathrm{HH}}=\right.$
$3.7 \mathrm{~Hz}), \quad 7.81 \quad\left(4 \mathrm{H}, \quad \mathrm{d}, \quad J_{\mathrm{HH}}=1.2 \mathrm{~Hz}\right), 7.84 \quad(1 \mathrm{H}, \mathrm{d}$, $J=2.5 \mathrm{~Hz}), 8.63(1 \mathrm{H}, \mathrm{s}), 8.67(1 \mathrm{H}, \mathrm{m}), 8.70(1 \mathrm{H}, \mathrm{m})$, $8.71(1 \mathrm{H}, \mathrm{m}) ; \mathrm{UV}_{\mathrm{abs}}\left(\mathrm{CHCl}_{3}\right) \lambda_{\max } 308 \mathrm{~nm}, 456 \mathrm{~nm}$. Accurate mass EI+: $562.1384 \Delta=-1.3 \mathrm{C}_{40} \mathrm{H}_{26} \mathrm{Fe}$.

Adaptation of the synthesis for the formation of the disubstituted ferrocenes $\mathbf{1 6}$ and $\mathbf{1 7}$ adding 5 equiv of the lithio alkynes to the bis-1,1'-(2-anthraquinolyl)ferrocene resulted in the formation of the products, representative data: 16: (yield: $54 \%$ ) ${ }^{1} \mathrm{H}$ NMR $\left(250 \mathrm{MHz}, \mathrm{CDCl}_{3}\right): 4.54$ (4H, br s), $4.88(4 \mathrm{H}$, br s), $7.37(20 \mathrm{H}, \mathrm{m}), 7.60(8 \mathrm{H}, \mathrm{m})$, $7.90(2 \mathrm{H}$, br s), $8.01(2 \mathrm{H}, \mathrm{m}), 8.09(2 \mathrm{H}, \mathrm{m}), 8.21(2 \mathrm{H}, \mathrm{m})$. ${ }^{13} \mathrm{C}$ NMR $\left(250 \mathrm{MHz}, \mathrm{CDCl}_{3}\right): 67.32,70.43$ (ferrocenyl $\alpha$ and $\beta C$ 's), 124.62, 125.77, 126.02, 126.92, 126.97, 128.11, $128.34,128.44,131.48,131.71$ (no quaternary C's observed). Accurate mass EI+: $938.263 \Delta=-1.3$ for $\mathrm{C}_{70} \mathrm{H}_{42} \mathrm{Fe}$

25. 1,1'-Bis(trans-2-[2-anthraquinonyl]vinyl)ferrocene, 18: [(2anthraquinonyl)-methyl]triphenylphosphonium bromide $(0.563 \mathrm{~g}, 1.0 \mathrm{mmol})$ was suspended in $50 \mathrm{~mL}$ of dry toluene. To the suspension was added potassium-tertbutoxide $(0.112 \mathrm{~g}, 1.0 \mathrm{mmol})$ and then the mixture heated to reflux for $1 \mathrm{~h}$. Next, a solution of $1,1^{\prime}$-ferrocenedicarbaldehyde $(0.121 \mathrm{~g}, 0.5 \mathrm{mmol})$ in $22 \mathrm{~mL}$ of dry toluene was added and the mixture was heated to reflux overnight. The solvent was then removed under vacuum and the residue was washed with $75 \mathrm{~mL}$ of water and afterwards dissolved in $75 \mathrm{~mL}$ of $\mathrm{CH}_{2} \mathrm{Cl}_{2}$. The solution was dried over $\mathrm{MgSO}_{4}$, filtered and the solvent evaporated. The resulting solid was purified by silica gel chromatography using petrol ether $40 / 60$ and dichloromethane $(1: 2 \mathrm{v} / \mathrm{v})$ with a gradient of ethyl acetate $2-25 \%$ as eluent. From the deep violet coloured main fraction the product crystallised out as small red crystals $(35 \%) .{ }^{1} \mathrm{H} \mathrm{NMR}\left(\mathrm{CDCl}_{3}, 500 \mathrm{MHz}\right)$ : $4.37\left(\mathrm{pt}, 4 \mathrm{H},{ }^{3,4} J_{\mathrm{HH}}=1.90 \mathrm{~Hz}, \mathrm{cp} / \mathrm{cp}^{\prime}: \mathrm{H}-2, \mathrm{H}-2^{\prime}, \mathrm{H}-5, \mathrm{H}-\right.$ $\left.5^{\prime}\right), 4.89\left(\right.$ pt $4 \mathrm{H},{ }^{3,4} J_{\mathrm{HH}}=1.90 \mathrm{~Hz}, \mathrm{cp} / \mathrm{cp}^{\prime}: \mathrm{H}-3, \mathrm{H}-3^{\prime}, \mathrm{H}-4$, $\left.\mathrm{H}-4^{\prime}\right), 6.48\left(\mathrm{~d}, 2 \mathrm{H},{ }^{3} J_{\text {trans }}=16.10 \mathrm{~Hz}\right.$, vinyl-H), $6.72(\mathrm{~d}, 2 \mathrm{H}$, ${ }^{3} J_{\text {trans }}=16.10 \mathrm{~Hz}$, vinyl-H), $7.41 \quad\left(\mathrm{dd}, 2 \mathrm{H},{ }^{4} J_{\mathrm{H} 3, \mathrm{H} 1}=\right.$ $1.85 \mathrm{~Hz},{ }^{3} J_{\mathrm{H} 3, \mathrm{H} 4}=7.90 \mathrm{~Hz}$, anthraquinonyl H-3), 7.58 $\left(\mathrm{cm}, 4 \mathrm{H}\right.$, anthraquinonyl-H), $7.77\left(\mathrm{~d}, 2 \mathrm{H},{ }^{4} J_{\mathrm{H} 1, \mathrm{H} 3}=\right.$ $1.85 \mathrm{~Hz}$, anthraquinonyl $\mathrm{H}-1), 7.84\left(\mathrm{~d}, 2 \mathrm{H},{ }^{3} J_{\mathrm{H} 4, \mathrm{H} 3}=\right.$ $7.90 \mathrm{~Hz}$, anthraquinonyl $\mathrm{H}-4), 7.87-7.89$ (m, 2H, anthraquinonyl-H), 7.98-8.00 (m, 2H, anthraquinonyl-H). 